3 Paolaggi J B, Chaouat D, Auquier L. An additional test for the diagnosis and monitoring of giant cell arteritis and polymyalgia rheumatica. Arth Rheum 1985; 28: $837-8$.

\section{Rheumatoid nodules}

The recent Leader on rheumatoid nodules by Veys and De Keyser ${ }^{1}$ gave a very interesting and useful review of the subject. When I was working as a medical registrar with $\mathrm{Dr}$ Bernard Schlesinger at the Royal Northern Hospital in pre-war London, one of my tasks was to carry out routine nodule counts on children with rheumatic fever (a not uncommon disorder in those days). Dr Schlesinger had found that these nodules, particularly in younger children with more serious disease, carried a worse cardiac prognosis. $^{2}$ At that time there was considerable interest in the possible relation of rheumatic fever to rheumatoid arthritis. A recent report by Fink $^{3}$ considers poststreptoccal reactive arthritis to be a form of rheumatic fever, though arthritis or arthralgia is of a more prolonged nature appearing early after infection.

Massell et al ${ }^{4}$ reported in 1937 that nodules closely resembling those of rheumatic fever could be produced by injecting $3 \mathrm{cc}$ of a patient's blood subcutaneously into the soft tissue of an elbow followed by rubbing the injected area six times daily; nodules appeared in 37 of 82 of their patients $(45 \%)$. I was unable to confirm these findings ${ }^{5}$ in 40 children with rheumatic fever in acute or convalescent stages, five children with chronic juvenile arthritis (Still's disease), and 10 adults with rheumatoid arthritis, three of whom had already developed rheumatoid nodules over one elbow. Veys and De Keyser report that rheumatoid nodules are found most commonly at sites of mechanical irritation and friction and we found the same to be true of nodules in rheumatic fever, but could not produce them experimentally.

Considerable interest was shown during the 1930 s and 1940s in rheumatoid nodule formation. Collins, ${ }^{6}$ Parkes Weber ${ }^{7}$ in the United Kingdom, and Horowitz ${ }^{8}$ in South Africa had worked and written on the subject, but my efforts to reproduce them experimentally failed miserably!

F DUDLEY HART 24 Harmont House, 20 Harley Street, 20 Harley Street,
London WIN $1 A N$, United Kingdom

1 Veys E M, De Keyser F. Rheuamtoid nodules: differential diagnosis and immunological findings. Ann Rheum Dis 1993; 52: 625-6.

2 Schlesinger B E. The public health aspects of heart disease in children. Lancet 1938; 1: 593-9, 649-54.

3 Fink $\mathrm{CW}$. The role of the streptococcus in poststreptococcal reactive arthritis in childhood polyarteritis nodosa. perspectives in paediatric rheumatology. $\mathcal{F}$ Rheumatol 1990 ; 18: (Suppl 29), 14-20.

4 Massell B F, Mote J R, Jones T D. four Clin Invest 1937; 16: 124-30.

5 Hart F D. Rheumatic subcutaneous nodule formation. Ann Rheum Dis 1939; 1: 196-200.

6 Collins D H. Observations on the pathology of acute rheumatism and rheumatoid arthritis. Ann Rheum Dis 1939; 1: 38-45.

7 Parkes Weber F. The nodules and lymph gland enlargement in rheumatoid arthritis Ann Rheum Dis 1944-5; 4: 3-10.

8 Horowitz $M$. The subcutaneous nodules of chronic rheumatoid arthritis: their clinical and pathological features. Clinical Proceedings 1949; 8: 73-116. 